\title{
Effects of transient soil waterlogging and its importance for rootstock selection
}

\author{
Michelle Morales-Olmedo ${ }^{*}$, Mauricio Ortiz ${ }^{1}$, and Gabriel Sellés ${ }^{2}$
}

Under transient waterlogging, a number of transformations in the soil are generated associated with lack of aeration, seriously affecting the root system. Significant progress has been reported on understanding the effects of lack of oxygen on the metabolism of the roots, although few studies have examined changes in the soil. Diverging conclusions about the degree of tolerance exhibited by plants exclude the effects of hypoxia and anoxia on physical-chemical soil properties under plant experiments. This review examines the main changes occurring in soil and roots due to transient soil waterlogging conditions. Parameters such as antioxidant capacity, nutrient uptake dynamics and regeneration and distribution of the root system are relevant for selecting rootstocks tolerant to soil waterlogging.

Key words: Root system, soil aeration, soil waterlogging, tolerance.

\section{INTRODUCTION}

The definition of soil waterlogging as a "plant stress" is considered to be the condition where the soil is fully saturated with water. This transient condition may be caused by a hindered flow of water through the soil profile or problems associated with a high water entry rate or a combination of both. In waterlogged soil, the diffusion of gases through soil pores is strongly inhibited by their water content that it fails to match the needs of growing roots. A slowed oxygen influx is the principal cause of injury to roots and the shoots they support (Vartapetian and Jackson, 1997). In some soils maintained at field capacity, the aeration is a limiting parameter for plant growth, and this can be a common problem in irrigation management. Some orchards can be flooded for 24 or $48 \mathrm{~h}$, by excess water, poor irrigation or absence of a proper drainage system, even in soils near field capacity (Ferreyra et al., 2011).

One of the main soil function is to provide a medium for plant growth; thus, modifications of its physical and chemical characteristics have a great impact on the development of the root biomass and consequently on plant vegetative development (Pierret et al., 2007). The soil should have adequate proportions of water and air in

\footnotetext{
${ }^{1}$ Centro de Estudios Avanzados en Fruticultura (CEAF), Camino Las Parcelas 882, sector Los Choapinos, Rengo, Chile.

"Corresponding author (mmorales@ceaf.cl).

${ }^{2}$ Instituto de Investigaciones Agropecuarias, INIA La Platina, Santa

Rosa 11610, La Pintana, Santiago, Chile.

Received: 15 December 2014.

Accepted: 23 April 2015
}

doi: $10.4067 /$ S0718-58392015000300006 the optimal range for the physiological performance of the plants. This balance may be altered by both natural and anthropic factors. Human-related causes include poor irrigation management and soil compaction, while natural flooding are caused by excessive rain (Irfan et al., 2010). In both cases soils with high clay content and/or compaction due to agricultural practices are susceptible to soil waterlogging. These effects contribute to limiting water and air movement in the soil, generating oxygen $\left(\mathrm{O}_{2}\right)$ deficiency and carbon dioxide $\left(\mathrm{CO}_{2}\right)$ accumulation (Kozlowski, 1997; Núñez-Elisea et al., 1999; Jackson and Colmer, 2005; Yetisir et al., 2006) as well as changes in the soils chemical properties (Unger and Kaspar, 1994). The gas exchange between soil and atmosphere in a wellaerated soil is sufficiently rapid to impede $\mathrm{O}_{2}$ deficiency and toxicity due to $\mathrm{CO}_{2}$ excess or other gases. The roots of most plants need a good supply of oxygen in order to satisfy the water and nutrient needs of the shoots, and the soil oxygen concentration should be above $0.1 \mathrm{~L} \mathrm{~L}^{-1}$ (Brady and Weil, 2008) $\left(\mathrm{O}_{2}\right.$ atmospheric concentration is $0.21 \mathrm{~L} \mathrm{~L}^{-1}$ ). A soil $\mathrm{O}_{2}$ concentration $<10 \%$ by volume indicates poor aeration for root growth. However, $\mathrm{O}_{2}$ concentration per se is an imperfect predictor of plant responses. The composition of other soil gases, such as $\mathrm{CO}_{2}$, ethylene, methane, etc., can affect the response to a given oxygen concentration (Sojka and Scott, 2000).

Since an oxygen decrease is one of the first effects of soil waterlogging, most published studies have evaluated the effect of hypoxia and anoxia on plants, either via hydroponic trials or using inert substrates (Morard and Silvestre, 1996; Striker, 2008; Arbona et al., 2009; Bai et al., 2013), but few studies have included the soil as a factor in their analyses. The absence of molecular oxygen triggers a sequence of changes in the physical-chemical 
properties of the soil. Many of these changes produce accumulation of reduced metal ions, organic and volatile acids, which are potentially damaging to plant roots. Their accumulation to phytotoxic levels requires time; however, the absence of oxygen alone is enough to alter plant metabolism to critical levels (Perata et al., 2011). These changes greatly affect the capacity of a plant to survive such conditions. As response, stomatal resistance increases, photosynthesis and root hydraulic conductivity decline and translocation of photoassimilates is reduced. Plants may adapt to hypoxic/anoxic conditions by changes in biochemical and metabolic processes when oxygen availability begins to be limiting (Dat et al., 2004). This review firstly describes how the main changes are induced under waterlogging stress, as well as parameters measured in studies of soil waterlogging. Secondly, this work discusses the effects of low soil oxygen concentration on plant responses that may be relevant for selecting plants tolerant to transient soil waterlogging.

\section{CHARACTERIZATION OF WATERLOGGED SOILS}

The composition of the soil gaseous phase is similar to that of the atmosphere, but differs in the proportions of oxygen, water vapor and $\mathrm{CO}_{2}$ depending on the depth and aeration conditions of each soil (Armstrong and Beckett, 2011).

Aeration implies soil ventilation by gas movement both to and from the soil, which determines the resulting velocity of gas exchange with the atmosphere, the proportion and composition of the soil air space and the oxidation-reduction potential in the soil environment (Brady and Weil, 2008). The $\mathrm{O}_{2}$ consumption and the $\mathrm{CO}_{2}$ production are caused by the respiration of plant roots in the soil, the activity of microorganisms and chemical reactions (Kozlowski, 1997; Núñez-Elisea et al., 1999). In a well-aerated soil, the $\mathrm{O}_{2}$ entrance and the $\mathrm{CO}_{2}$ outflow are sufficiently rapid to impede oxygen deficiency and toxicity due to $\mathrm{CO}_{2}$ excess. Normally, when more than $90 \%$ of the porous space in the soil is full of water, lack of aeration is a serious impediment to root growth due to low oxygen availability (Dexter, 1988; Cook and Knight, 2003), since the water blocks the gas diffusion pathways to and from the atmosphere (Kozlowski, 1997; Jackson and Colmer, 2005).

The movement of gases in the soil is a dynamic phenomenon in which gases are transported mainly by diffusion; the main parameter to consider is the gas diffusion coefficient in the soil, which depends on texture, structure, distribution, size and pores connectivity, and tortuosity (Moldrup et al., 2000; 2001). Thus, an increase in pores saturated with water decreases oxygen movement, since diffusion in water is 10000 times slower than in air (Moldrup et al., 2000; Nickum et al., 2010), producing an anaerobic environment in a few hours if the oxygen is consumed by the activity of microorganisms and roots (Drew, 1992; Nickum et al., 2010).

When the soil pores are saturated with water, there are a series of chemical modifications such as alterations in $\mathrm{pH}$ and the accumulation of toxic products for the roots, such as reduced metal ions, organic and volatile acids and reactive oxygen species (ROS), which are important in the response and capture of signals for the subsequent adjustment of the plant (Irfan et al., 2010). Accordingly, the magnitude of waterlogging in the soil can be characterized through the soil porosity, oxygen diffusion rate, redox potential and the composition of gases in the soil.

\section{Total porosity of the soil}

The optimal soil composition for plant growth should contain about $50 \%$ solid and $50 \%$ pore space. Within the pore space, the mixture of air and water should be close to 50:50; hence, $25 \%$ of the soil volume should be occupied by air. Gas diffusion is conditioned by the physical properties of the soil, among which soil porosity is one of the most important, especially the fraction with air (Hillel, 1980). In the majority of soils, microbiological activity and plant growth are seriously inhibited when the porosity with air decreases to less than $20 \%$ of the pore space, which is related to soil properties such as texture, structure, water content, mineralogy of clays and sodium adsorption relation (Pezeshki et al., 1996; Brady and Weil, 2008; Tete et al., 2015).

Sandy soils have less total porosity than clays, but the pores are larger and well connected in sand. In finetextured soils, the percentage of space with air tends to decrease when they are poorly structured, since clays have many small, discontinuous pores and retain water more easily than soils with coarser texture. Thus, plants tend to suffer oxygen limitation more frequently in clay soils in spite of their greater total porosity (Sojka and Scott, 2000). When a large amount of water is applied to the soil, greater than its retention capacity, water excess usually drains; however, when the texture is fine with a tendency to compaction or hanging strata that impede drainage, water is retained for a longer time, producing extended saturation of the pore space. In this first stage, the immediate consequence of inundation is the blockage of gas interchange with the atmosphere and extreme slowing of atmospheric interchange with the gases in the water, especially oxygen.

\section{Oxygen diffusion rate}

The oxygen diffusion rate is a measure of the mobility of this gas in the soil (Logsdon, 2003) and is of great importance for its supply to the roots. The Oxygen Diffusion Rate (ODR) measurement method consists of quantifying the electrical current necessary to reduce all the available oxygen on the surface of a platinum electrode placed in the soil. Studies on the responses of 
plants to excess water indicate a threshold rate of oxygen diffusion rate of $0.2 \mu \mathrm{g} \mathrm{cm}^{-2} \mathrm{~min}^{-1}$. Below this value there is growth retardation and considerable damage to the roots of most cultivated plants (Valoras et al., 1964; Stolzy et al., 1967; Jacobs et al., 1997; Ferreyra et al., 2011). Given the same porosity, oxygen diffusion is less in humid soils compared to dry soils, which have a larger percentage of their pores filled with air (Moldrup et al., 2000; Feng et al., 2002). Although a portion of the oxygen necessary for root development may be obtained from the aqueous solution in which it is dissolved, this represents only a small fraction of the total required. This is because most of the oxygen in the root zone must diffuse from the atmosphere to the soil through the pore spaces, and then diffuse through a film of water that surrounds the roots and into the roots to be utilized (Cook and Knight, 2003).

Once the oxygen begins to be used, this measurement loses relevance when the soil is waterlogged, since the majority of the pores are full of water and diffusion approaches zero (Wu et al., 2003). In parallel, changes in the redox potential $\left(\mathrm{E}_{\mathrm{h}}\right)$ are triggered, which makes this a good alternative to evaluate the aeration state of the soil.

\section{Redox potential}

The redox potential $\left(E_{h}\right)$ provides a measure of the tendency of a substance to accept or donate electrons, and is one of the most appropriate indicators of the chemical changes produced during waterlogging of the soil (Pezeshki and DeLaune, 1998). The $\mathrm{E}_{\mathrm{h}}$ of a soil depends both on the presence of an electron acceptor (oxygen or another oxidizing agent) and the $\mathrm{pH}$; it is usually measured in volts or millivolts $(\mathrm{mV})$. In a well-drained soil $\mathrm{E}_{\mathrm{h}}$ is in the range of +400 to $+700 \mathrm{mV}$, while in waterlogged soils $\mathrm{E}_{\mathrm{h}}$ decreases to a range of +400 to $-300 \mathrm{mV}$. Generally, when oxygen is not present soil values of $\mathrm{E}_{\mathrm{h}}$ are below +350 mV (DeLaune et al., 1990; Pezeshki, 2001), while in waterlogged soils that are warm and rich in organic material, values may be as low as $-300 \mathrm{mV}$ (Brady and Weil, 2008).

Since both $\mathrm{E}_{\mathrm{h}}$ and $\mathrm{pH}$ are easily measured, it is possible to infer the redox reaction of an element in the soil. For example, in a soil with $\mathrm{pH} 6$, the $\mathrm{E}_{\mathrm{h}}$ should be less than $+0.5 \mathrm{~V}$ to stimulate the reduction of nitrates to nitrites, and approximately $+0.2 \mathrm{~V}$ to stimulate the reduction of $\mathrm{FeOOH}$ to the $\mathrm{Fe}^{2+}$ ion. To form methane in a waterlogged soil at this same $\mathrm{pH}$, an $\mathrm{E}_{h}$ equivalent to approximately $-0.2 \mathrm{~V}$ is needed (Figure 1) (McBride, 1994).

Since $\mathrm{O}_{2}$ is reduced to water by aerobic microorganisms when the value of $E_{h}$ is +380 to $+320 \mathrm{mV}$, once the redox potential is below this range there is almost no $\mathrm{O}_{2}$ in the soil (Pezeshki, 2001). With even lower levels of $\mathrm{E}_{\mathrm{h}}$ (anoxia), the only active microorganisms are those that can use other metabolic electron acceptors instead of oxygen. The element that usually follows is $\mathrm{N}$ (nitrates, $\mathrm{NO}_{3}^{-}$), due to its ease of reduction. If the soil has abundant nitrate, while this is being reduced, $\mathrm{E}_{\mathrm{h}}$ will remain in the range of +280

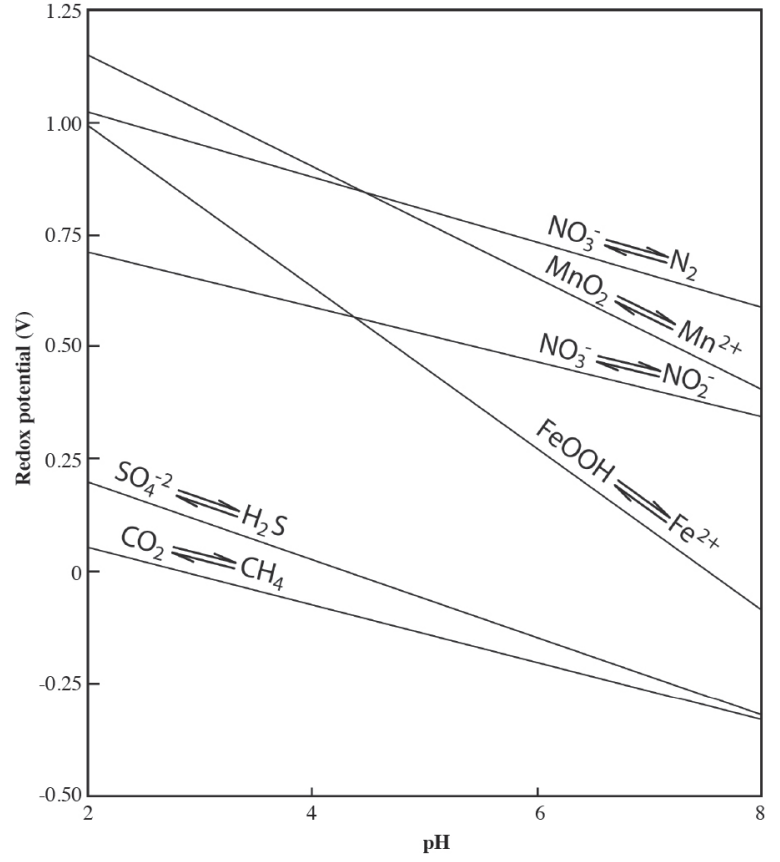

Adapted from McBride (1994).

Figure 1. Effect of $\mathrm{pH}$ on the redox potential (Condon and Richards, 1992) at which various oxidation-reduction reactions are generated in soils.

to $+220 \mathrm{mV}$. When almost the entire supply of nitrate has disappeared, $\mathrm{E}_{\mathrm{h}}$ will fall even further. At this point organisms capable of reducing Mn will become active, and so on. Thus, as the value of $\mathrm{E}_{\mathrm{h}}$ falls, the elements $\mathrm{N}$, $\mathrm{Mn}, \mathrm{Fe}, \mathrm{S}$ (in $\mathrm{SO}_{4}{ }^{2-}$ ) and $\mathrm{C}$ (in $\mathrm{CO}_{2}$ ) accept electrons and are transformed into reduced elements, almost always in this order (McBride, 1994). Accordingly, $\mathrm{E}_{\mathrm{h}}$ is not only an indicator of the oxygen level in the soil, but also of the availability and concentration of different plant nutrients indirectly (Pezeshki, 2001). Likewise, the redox condition and slow diffusion of oxygen in the soil accelerate the accumulation of nutrients and/or toxic gases, as well as the production and accumulation of ethylene, which is important for the plant responses.

\section{Composition of gases in the soil}

As a result of the aerobic respiration of plant roots and microorganisms, soil atmosphere is characterized by the enrichment in $\mathrm{CO}_{2}$ and poor in oxygen. However, when the soil is saturated (anaerobic), other gases appear in the soil such as nitrous oxide, gaseous $\mathrm{N}$, and methane as a result of anaerobic bacterial respiration.

Oxygen. The $\mathrm{O}_{2}$ concentration may be slightly less than $20 \%$ in the upper levels of a soil with a stable structure and an abundance of micropores (atmosphere has about $21 \% \mathrm{O}_{2}$ ). In the inferior horizons of poorly drained soils with few micropores it may fall to less than $5 \%$, or even close to 0 (Brady and Weil, 2008). Low $\mathrm{O}_{2}$ content is 
typical of humid soils, although in well-drained soils after heavy rains air $\mathrm{O}_{2}$ content may be considerably reduced, especially if it is being rapidly consumed by actively growing plant roots or microorganisms that decompose organic matter. Also, if the soil temperature is high then oxygen is depleted more rapidly due to acceleration of the metabolic activity of microorganisms. When all the soil pores are full of water, microorganisms may remove the majority of the oxygen dissolved in the water; however, this small amount of dissolved $\mathrm{O}_{2}$ is rapidly depleted. Accordingly, if the excess water is not removed the aerobic activity of microorganisms and plant growth are endangered.

Carbon dioxide. Whereas $\mathrm{N}_{2}$ content of the soil air is relatively constant, there is generally an inverse relation between the other two principal components, $\mathrm{O}_{2}$ and $\mathrm{CO}_{2}$; $\mathrm{O}_{2}$ decreases as $\mathrm{CO}_{2}$ increases. Although the absolute differences in the $\mathrm{CO}_{2}$ quantity may not be considerable, their proportional changes may be very relevant; for example, when soil air only has $0.35 \% \mathrm{CO}_{2}$, this gas is still about 10 fold more concentrated than in the atmosphere $\left(0.035 \% \mathrm{CO}_{2}\right)$. When soil water increases the air space in the pores decreases, which limits the diffusion of $\mathrm{CO}_{2}$, increasing its accumulation (Bouma and Bryla, 2000). When the $\mathrm{CO}_{2}$ concentration is as high as $10 \%$, it may be toxic for some plant processes.

Other gases. In waterlogged conditions, the concentrations of some gases that form due to the decomposition of organic material such as methane $\left(\mathrm{CH}_{4}\right)$ and hydrogen sulfide $\left(\mathrm{H}_{2} \mathrm{~S}\right)$ are notably greater in the soil atmosphere. Another gas produced by anaerobic microbial metabolism is ethylene $\left(\mathrm{C}_{2} \mathrm{H}_{4}\right)$, which is particularly toxic for plant roots even though it is present at concentrations less than $1 \mu \mathrm{L} \mathrm{L}^{-1}(0.0001 \%$ or $1 \mathrm{ppm})$. This molecule is indeed a plant hormone capable of influencing processes such as cell expansion, senescence and differentiation at relatively low concentrations (0.01-10 ppm, v/v) (Jackson, 2005). It has been shown that when velocity of gas interchange between soil and atmosphere is too slow, the accumulation of ethylene inhibits the root growth of several plants, but also induces morphological and anatomical changes such as the aerenchyma formation and adventitious roots (Visser and Voesenek, 2005). Similarly, gases such as methane and nitrous oxide are generated or absorbed in the soil depending upon the redox potential under certain aeration conditions. The formation of nitrous oxide is due to processes of de-nitrification in anoxia and nitrification under oxidative soil conditions (Gliński and Stepniewski, 1985 ), or a combination of both processes under hypoxic conditions (Zschornack et al., 2011). Methane is generated under more intense reduction conditions that occur at values of less than $-150 \mathrm{mV}$ (Stępniewski and Stępniewska, 2009).

\section{Factors determining soil aeration and root growth}

Soils are normally described based on a set of physical properties, including structure, texture, bulk density, pore distribution, and size and morphological characteristics of the profile. However, it is necessary to separate factors that directly affect plant growth from those that indirectly affect plant growth. Water, oxygen, temperature, and mechanical resistance can impair root growth and directly affect plant growth (Figure 2) as a consequence of interactions with the indirect factors mentioned above and

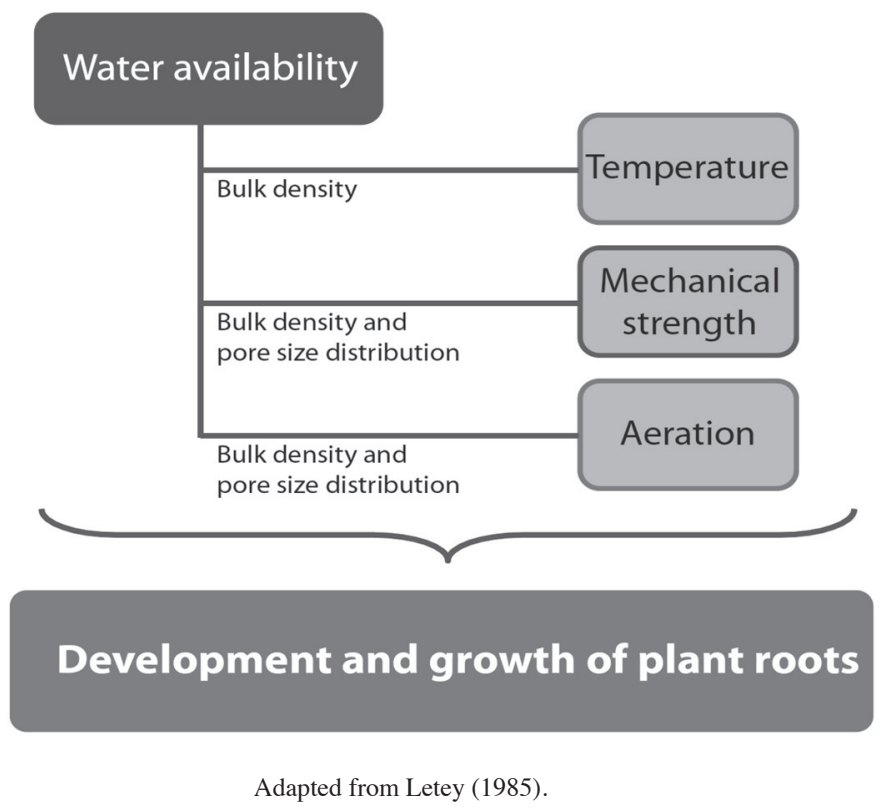

Figure 2. Relationships between water and other physical soil parameters that directly affect root development and plant productivity. 
the management practices used (Letey, 1985; Wu et al., 2003). The soil physical factors are considered interrelated and never independent of each other. Of the four physical conditions directly related to root development, water is the dominant controlling factor. The relationship between water and aeration is opposed to that between water and mechanical resistance. Increasing water content decreases aeration, which is undesirable but in turn decreases mechanical resistance, which is desirable. The effect of water on both these parameters is intensified by increases in bulk density and/or the presence of small pores. The water-temperature $v s$. water-mechanical resistance interrelationship has a similar interpretation (Letey, 1985). Maintaining a relatively high water content at the beginning of spring without affecting gas transport in order to reduce mechanical resistance leads to a colder or harder to heat soil. Relatively low soil temperature, in turn, will produce less metabolic activity in roots.

Modification of these factors also affects the geometry of the pores, producing a decrease in macropores and an increase in micropores (Letey, 1985). Excess water generated by poor irrigation management, soils with low permeability, poor drainage, fine textures and poorly structured soils with discontinuous pores may facilitate the rapid and permanent saturation of soil pores.

The optimum values mentioned by a number of authors (Dexter, 1988, Bengough et al., 2006; Whitmore and Whalley, 2009) are $15 \%$ air content in the soil, oxygen diffusion greater than $0.2 \mu \mathrm{g} \mathrm{cm}^{-2} \mathrm{~min}^{-1}$ and less than $2 \mathrm{MPa}$ resistance to root penetration for the majority of species. The optimum range of water content for plant growth has generally been established using criteria based on water availability (WA). The upper limit of WA is associated with field capacity (FC) and the lower limit with the permanent wilting point (PWP); under this criterion, irrigation is performed each time the soil exhausts a fraction of the WA (Letey, 1985). Although these thresholds may be useful as a tool for empirical management, they are less useful to identify critical values or soil water tension, which limit plant growth and allow optimization of the soil-plant interaction to maximize yield and quality (Whitmore and Whalley, 2009). Letey (1985) introduced the concept of non-limiting water range (NLWR), which established upper and lower limits of soil water content within which air and mechanical resistance do not affect plant growth. The NLWR may be considered a soil quality index in which a wide range is desirable, since in soils with very low NLWR it is difficult to sustain water content in a range that does not affect the development of the root system, due either to deficient aeration or an increase in soil mechanical resistance (Figure 3).

Da Silva and Kay (1997a) applied the conceptual framework of Letey's NLWR, and renamed it as the least limiting water range (LLWR), demonstrating that apparent density strongly affects the LLWR. These authors indicated that an increase in bulk density decreased the

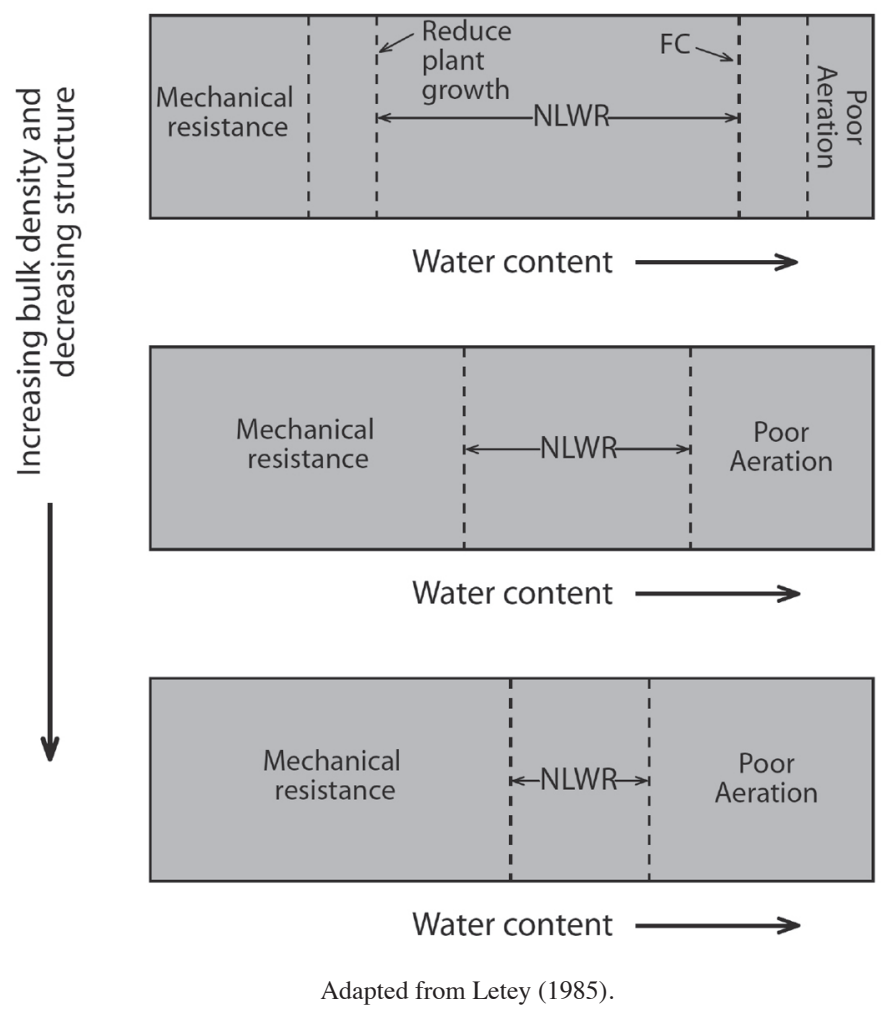

Figure 3. Non-limiting water range for plants (NLWR). 
LLWR, and in soils with equal bulk density this range is smaller when the proportion of clay increases and organic material decreases (da Silva and Kay, 1997a). Under field conditions, given the large temporal variability, there is a very high probability that water content is outside the optimum range (Figure 4) (da Silva and Kay, 1997b).

The soil physical parameters undoubtedly play an important role in problems of soil aeration, due to either lack (mechanical resistance and compaction) or an excess (lack of oxygen and inundation) of water. Jones et al. (1991) investigated root growth in different soil textures and established ranges of relative aeration (air pore volume/total porosity); when this value is less than $38 \%$, relative root growth decreases to less than $80 \%$. For total soil porosity equivalent to $40 \%$, the air space should be greater than $15 \%$ so the root growth is not limited, while for a clay soil with a porosity of $50 \%$ this limit would be 19\% (Figure 5).

Furthermore, Imhoff et al. (2010) established a range of $15 \%$ to $20 \%$ of soil aeration for maize, so necessarily the air requirements should be about $15 \%$ as an upper limit, or even lower for sensitive crops (Bartholomeus et al., 2008; Mohammadi et al., 2010). However, this limit is not an intrinsic, unchanging characteristic of the soil and can fluctuate depending on: 1) The demand for oxygen by roots and soil biota, in turn depends on temperature and root mass; 2) depth at which gas exchange is studied, and 3 ) the interconnected water-free porous matrix (Pilatti et al., 2012).

\section{Changes in roots under flooded conditions}

As previously mentioned, changes in the soil during an inundation event are relevant to the response of plants and their level of tolerance. Plants differ in their stress tolerance, which is the capacity of a plant to confront an unfavorable environment. If the exposure to stress is greater and tolerance increases, maintaining the plant in a good state, it is called acclimated. The adaptive response, in contrast to acclimation, is related to a level of resistance conferred genetically and acquired after selection processes lasting over many generations. Adaptation and acclimation to stressful environments are a result of integrated events that occur at all levels of organization, from anatomical and morphological to the cellular, biochemical, and molecular levels (Taiz and Zeiger, 2010).

Stress parameters related to plant survival, productivity, and growth (accumulation of biomass), or processes of primary assimilation related to overall growth $\left(\mathrm{CO}_{2}\right.$ and nutrient consumption), are used to measure their impact (Taiz and Zeiger, 2010; Pimentel et al., 2014). The immediate consequence of soil waterlogging is a period of hypoxia followed by a strong decrease in oxygen, which leads to anoxic conditions that activate the anaerobic fermentation pathway (Blom and Voesenek, 1996). Thus, when the oxygen supply is insufficient for aerobic respiration, roots begin to ferment pyruvate (formed in glycolysis) to lactate by the action of lactate dehydrogenase ( $\mathrm{LDH})$. Lactic fermentation is

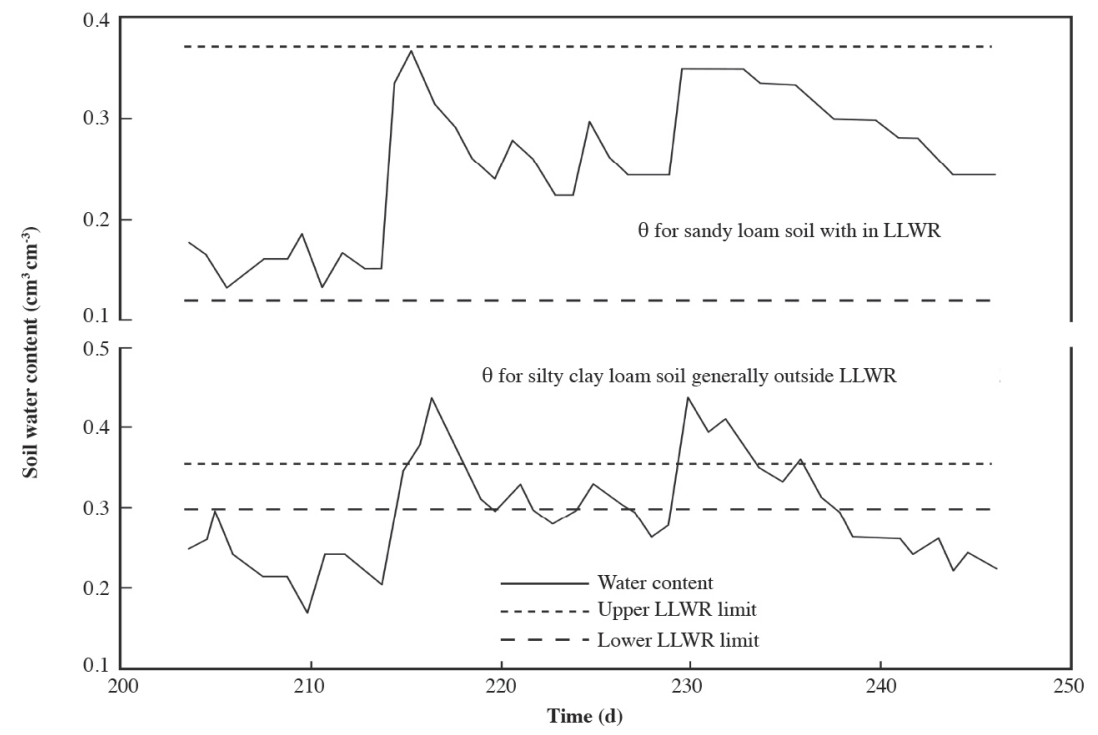

Redrawn from da Silva and Kay (1997).

Figure 4. Least limiting water range (LLWR). Comparison of two soils in relation to water content and time. 


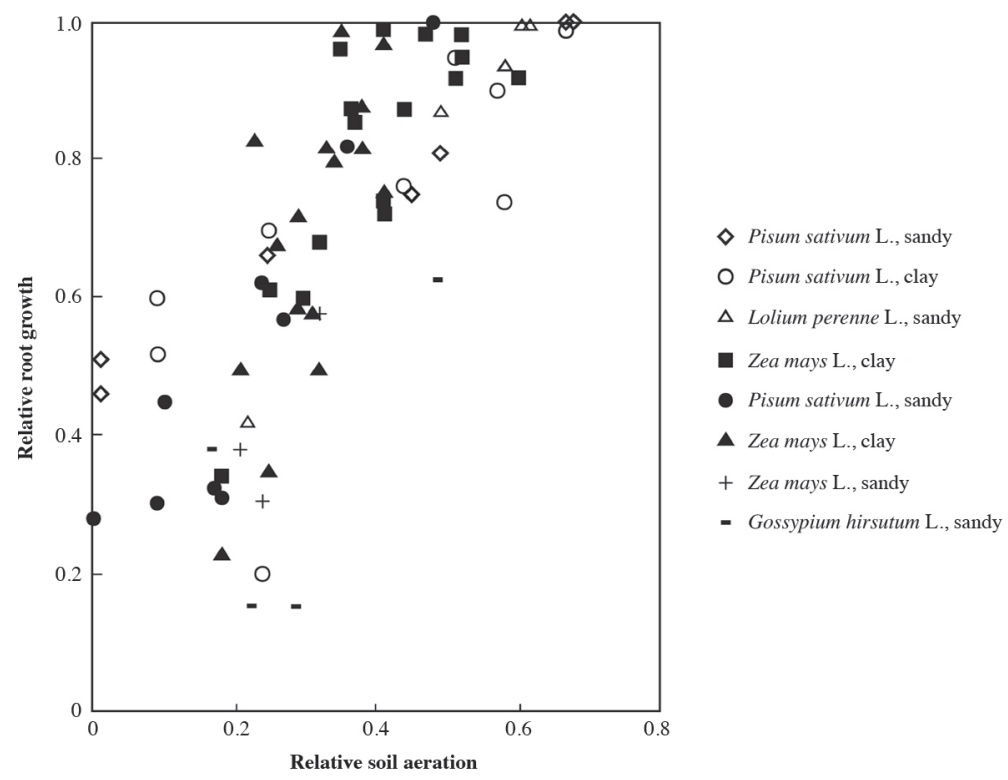

Source: Adapted from Jones et al. (1991).

Figure 5. Relative root growth of various crops on soils with contrasting textures as a function of the relative soil aeration (air pores/total porosity).

transient, because a rapid decrease in intra-cellular $\mathrm{pH}$ leads to a switch from lactate fermentation to ethanol fermentation, since the enzymes for these metabolic pathways differ in their optimum $\mathrm{pH}$ for functioning. In acid $\mathrm{pH}, \mathrm{LDH}$ is inhibited and pyruvate decarboxylase is activated. Net ATP production in anaerobic fermentation is only 2 mol ATP per mol of hexose metabolized, compared to 36 mol ATP produced per mol of hexose in aerobic respiration (Taiz and Zeiger, 2010). The attempt to compensate for the reduced ATP production by fermentation accelerates glycolysis, leading to an exhaustion of carbohydrate reserves (Pasteur effect). Species tolerant to soil waterlogging are generally considered those that are capable of maintaining their energetic state by the fermentation pathway (Drew, 1997).

In hypoxic or anoxic roots energy is insufficient to support physiological processes in shoots necessary for their functioning. Experiments have shown that difficulties of wheat and barley in absorbing nutrients and transporting them via xylem rapidly lead to an ion shortage for tissue development and plant expansion. Mature leaves become senescent prematurely due to the relocation of mobile nutrients of the phloem $(\mathrm{N}, \mathrm{P}$, and $\mathrm{K})$ to younger leaves. The low permeability of roots to water frequently leads to a decrease in leaf water potential and withering, although this decrease is temporary if the stomata close, preventing further loss of water by transpiration (Taiz and Zeiger, 2010).

Also, the reduced condition of soil and consequent decrease in its capacity for nutrient extraction will tend to limit $\mathrm{N}$ and $\mathrm{P}$ content of the plant. By contrast, $\mathrm{Fe}$ and Mn availability in soil will increase, since they are reduced to more soluble forms. This sudden availability or restriction of various elements will drastically affect the root metabolism (Drew, 1997).

Hypoxia also accelerates production of the ethylene precursor of 1-aminocyclopropane-1-carboxylic acid (ACC) in roots. In tomato ACC travels through the xylem sap to buds, where in contact with oxygen it is converted to ethylene by the action of ACC oxidase. In some species such as peas and tomatoes, waterlogging induces stomatal closure, apparently without detectable changes in the water potential of leaves. The scarcity of oxygen in leaves, as with water deficit and salt accumulation, may stimulate the production of abscisic acid (ABA) and its movement to leaves. However, stomatal closure may be mostly attributed to additional production of ABA by less mature leaves. These leaves wither and export their ABA to turgid young leaves, producing stomatal closure (Zhang and Zhang, 1994).

The slow diffusion of gases in water will accelerate the accumulation of potentially phytotoxic products of anaerobic metabolism such as ethanol, lactic acid, $\mathrm{CO}_{2}$, $\mathrm{N}_{2}, \mathrm{H}^{+}$, and methane. These may accumulate within cells and/or be liberated in the soil solution and adversely alter soil chemical properties. Organic acids with low volatility (propionic and butyric acid) may accumulate in waterlogged soils. In a situation of re-aeration after a period of oxygen privation, the remnant ethanol in tissues may be converted to acetaldehyde, which may induce post-anoxic cell damage (Bailey-Serres and Voesenek, 2008). Along with this, alterations in oxygen availability in the soil may induce the proliferation of reactive excited 
states such as reactive oxygen species (ROS); these may be superoxide radicals, hydrogen peroxide or oxygen singlets. ROS are produced by normal cell metabolism in a plant, but under stress conditions the relation between their synthesis and elimination is altered (Blokhina et al., 2003).

\section{Transient soil waterlogging and selection of tolerant rootstocks}

Most studies of the effects of waterlogged soils on plants have been focused on annual species such as rice, maize, subterranean clover, and alfalfa (Vartapetian and Jackson, 1997) under completely waterlogged conditions. A small number of reports have dealt with the effect produced in woody trees, but there has been little research on fruit trees. Additionally, the type of inundation to which plants are exposed will mostly determine the response mechanisms and adaptations evolved by the species, which are necessary to determine for selecting tolerant plants. The responses and adaptation mechanisms of plants in wetland ecosystems may serve as models, but these species have different mechanisms than plants that have evolved in soils without free water. Most studies have dealt with the effects of continuous waterlogging, not transient situations, in which long-term mechanisms of adaptation or acclimation such as the generation of aerenchyma, hypertrophied lenticels, and adventitious roots become much more important for plant survival.

In Chile, the origin of aeration deficiency in agricultural soils is mainly related to poor management of fine-textured soils, which are subject to compaction. The saturation of the pores produces situations where hours or days pass with little or no oxygen available for the normal development of plants. This problem is more complex when the limits of soil density and structure increase, sometimes reaching reduced values of LLWR, in which small errors in irrigation management inevitably generate hypoxia and/or anoxia.

Current technological tools allow continuous monitoring of water level in soil using water content sensors. These provide information to the depth to which roots are, as well as avoiding excessive water levels by adjusting the application and frequency of irrigation (Schaffer, 1998). One of the main difficulties with the attempt to have a wider vision of the effects of oxygen deficiency in the soil due to the effect of transient conditions of waterlogging is precisely that of including the soil factor in the soil-root interactions. So far there have been significant advances in the detailed study of lack of oxygenation in roots of different species of plant in soilless culture systems (hydroponics and aeroponics), especially in annual species in which it is possible to simulate oxygen deficiency and its effects on nutritional balance (Morard and Silvestre, 1996; Bertholdsson, 2013). However, these methodologies ignore a series of modifications in the soil which may be relevant in field conditions for the adjustment of the plant, such as other gases in the pore spaces (not only oxygen) and the physical structure of the soil mentioned above, which affect root growth (root anatomy and root system architecture) in ways that are impossible to simulate in hydroponic systems. The use of pots with substrate or soil may provide better information with respect to the soil-root interaction for the selection of parameters or mechanisms of adaptation.

In fruit trees, studying the root responses to temporal waterlogging is very relevant, since the development of the aerial part of the plant depends largely on the rootstock employed (Schaffer, 1998). The selection of the scion is thus a relevant and strategic decision for the design and establishment of a fruit tree orchard. From the physiological perspective, tolerance to waterlogging has been defined in studies oriented to the survival or maintenance of growth rates in this condition compared to a control without inundation. The agronomical definition is based on productivity, which refers to the possibility that a cultivar tolerant to waterlogging exhibit a mechanism associated with escape from anaerobic conditions, either due to dormancy or slower growth during the stress and a rapid resume when the stress ends (Setter and Waters, 2003). In rootstock breeding programs yield is not essential, but physiological and morphological traits (or features) of root system that reduce negative effects of waterlogging are important. Accordingly, for the selection of plants tolerant to abiotic stress it is important that the key trait can be selected with precision; in this case it could be related to the root energy balance. Once plants are selected for this characteristic, other features required for establishment at field conditions may be included. In a second stage of tolerant rootstock selection to transient waterlogging, soil factor is essential, especially its relation with dynamics of gas exchange and toxic compounds produced in the soil under waterlogged conditions. In a hydroponic system, $\mathrm{N}$ is pumped in to displace the oxygen present, in order to maintain low oxygen content. Although this technique allows the maintenance of precise oxygen concentration in a trial, it removes most of the gases produced close to the root. Under natural conditions, the water block in the upper soil layers does not allow rapid gas exchange and compounds begin to accumulate and may become toxic for the plant or modify its response pathways. Although closed hydroponic systems allow progressive exhaustion of oxygen due to the respiration of the plant itself, resembling natural conditions, results must be carefully validated in a soil system (Morard and Silvestre, 1996).

The plant tolerance to inundation is quite variable and depends upon the species, genotype, age, timing and duration of the stress, and water quality of the waterlogging. Moreover, the susceptibility of a species varies depending on the criterion by which tolerance is evaluated. For example, two species of Parkia ( $P$. pendula and $P$. discolor) showed similar tolerance levels 
in germination, but contrasting responses when seedling survival was used as a criterion of adaptation (Scarano and Crawford, 1992). Due to this filter, the rootstock tolerance classification depends upon factors such as type of waterlogging (gradual or complete), number of days waterlogged (short- and long-term evaluations) (Striegler et al., 1993; Kozlowski, 1997; Schaffer, 1998), with or without soil (Tavakkoli et al., 2010) and with or without recovery (Striker, 2012), all of which make it difficult to have uniform criteria for the selection of tolerant plants and to distinguish plants adapted to waterlogging stress under field conditions (Striegler et al., 1993; Ranney, 1994).

Most studies, however, consider a permanent flooding stress but in field conditions plants are often exposed to intermittent episodes of flooding and recovery. This transient waterlogging is very important because some specific damages, such as oxidative stress, may occur to a higher extent during re-aeration of tissues after a period of stress. Therefore ROS metabolism is an important tolerance criterion for rootstocks. One protection system against ROS is superoxide dismutase (SOD), an enzyme that converts superoxide radicals to hydrogen peroxide, which is reduced to water by peroxidases or catalase (Drew, 1997; Blokhina et al., 2003). In Citrus species has been demonstrated that waterlogging generates oxidative damage; however, the damage was reduced and delayed in rootstocks tolerant to waterlogging compared to more sensitive rootstocks. Although SOD activity is directly related to protection from oxidative damage, the activity of ascorbate peroxidase and catalase are strongly increased in tolerant species, avoiding the accumulation of hydrogen peroxide generated by SOD (Arbona et al., 2008); similar results were found in apple (Bai et al., 2010). Accordingly, the cause of the damage to plants in waterlogged soils is frequently questioned. The literature suggests that it is more related to the production of toxic substances than to oxygen deficiency in the roots per se (Setter et al., 2009). In agreement with this, another aspect that may be relevant to consider in rootstock selection is the generation of reduced compounds in the soil such as $\mathrm{Fe}^{+2}$, which change remarkably after an inundation event (Brzezińska et al., 2005). It would be interesting to obtain rootstocks capable of tolerating ferric chlorosis, since in perennial species sensitive to waterlogging such as avocado, one of the most common consequences after stomatal closure is leaf chlorosis (Fassio et al., 2011). In more tolerant species such as grapevine this has not been clearly demonstrated. Another alternative would be to search for genotypes efficient in nutrient use in situations of waterlogging, such as the efficient $\mathrm{N}$ use to maintain growth and metabolic activity under stress, although a direct relation between high vigor and tolerance to waterlogging is not clear.

The dynamics of root growth and the ability of trees to recover from transient inundations are significant in evaluating short-term effects of waterlogging (Smith et al., 1990). Species reduce their growth under anoxic conditions, but in contrast to sensitive species, tolerant species can resume growth rapidly once aeration has been restored. Studies in peach showed that the generation of new roots is key for recovery from the damage produced by short-term waterlogging, and can be achieved after 16 d (Nicolás et al., 2005). A similar response was found in almonds (Prunus dulcis (Mill.) D.A. Webb) (SanchezBlanco et al., 1994), with recovery after $20 \mathrm{~d}$, and also after 29 d in lemon grafted on Citrus aurantium L. (RuizSanchez et al., 1996). It has also been observed in species such as blue oak (Quercus douglasii Hook. \& Arn.) that root systems with few ramifications or lateral roots are more sensitive to hypoxia due to their reduced ability to absorb oxygen (Jacobs et al., 1997), which has also been reported for other species such as Eucalyptus and Picea (Philipson and Coutts, 1978; Kozlowski, 1985). Currently, with new tools for observation of roots in situ using scanners, these parameters may be evaluated both in potted soil and in the field.

Another feature of rootstocks is susceptibility to diseases, principally fungi of the genus Phytophthora, which is strongly associated with waterlogged soils. It has been observed that when this fungus is present in avocados, there is greater damage to photosynthesis and gas interchange (Ploetz and Schaffer, 1989; Schaffer and Ploetz, 1989; Schaffer, 1998); therefore, it is recommended to include rootstock susceptibility to this fungus in breeding programs.

Selection of rootstocks is complex, especially if a multifaceted stress such as transiently waterlogged soils is considered, since factors in the plant interact with soil factors. Hence, information on stress tolerance is not comparable and may appear contradictory. Most stresses do not have a single response pathway, but rather are integrated responses, even more so in the case of transient cycles of oxygen absence. This was corroborated by studies in wheat, where the tolerance of one wheat genotype was variable in two different waterlogged soils (Setter et al., 2009); in the other hand, the response of barley was different when grown in hydroponics or in soil (Tavakkoli et al., 2010), which indicates that we must continue to search for parameters or regulation mechanisms to select and adapt rootstocks to transient inundations, incorporating the soil in the studies.

\section{CONCLUSIONS}

Significant advances in the last decade have allowed us to discover responses, mechanisms, and adaptations to stress due to hypoxia/anoxia in plants of different species under controlled trial conditions. To select rootstocks for fruit trees it is necessary to evaluate the trees in semicontrolled conditions including the soil factor, considering large changes generated in soil by excess water. Although 
including soil in trials tends to be costly in terms of reducing precision in the treatments and producing a compounding effect of factors, from the agronomic perspective integrating the soil allows a better simulation of the effects of waterlogging stress in plants. Furthermore, the selection of parameters related to events that occur in soil and cannot be captured in closed hydroponic systems may enrich studies associated to rootstocks selection tolerant to waterlogging. In soils with transient waterlogging due to poor management and/or excessive rains, the selection of tolerant rootstocks should consider mechanisms of shortterm adaptation, like root mechanisms that respond to changes in the soil such as anti-oxidant capacity and the dynamics of nutrient absorption, as well as the regeneration and distribution of the root system architecture in soils susceptible to waterlogging. Research platforms using soils that can maintain different levels of aeration and monitor water and oxygen content and root growth, as well as measuring the suggested parameters, would be an important advance for rootstock breeding programs in the stage of evaluating waterlogging tolerance and their future field establishment and performance.

\section{ACKNOWLEDGEMENTS}

We thank the Centro de Estudios Avanzados en Fruticultura (CEAF), and CONICYT Regional project R08I1001 for financing this review.

\section{LITERATURE CITED}

Arbona, V., Z. Hossain, M.F. López-Climent, R.M. Pérez-Clemente, and A. Gómez-Cadenas. 2008. Antioxidant enzymatic activity is linked to waterlogging stress tolerance in citrus. Physiologia Plantarum 132:452-466.

Arbona, V., M.F. López-Climent, R.M. Pérez-Clemente, and A. Gómez-Cadenas. 2009. Maintenance of a high photosynthetic performance is linked to flooding tolerance in citrus. Environmental and Experimental Botany 66:135-142.

Armstrong, W., and P.M. Beckett. 2011. Experimental and modelling data contradict the idea of respiratory downregulation in plant tissues at an internal $\left[\mathrm{O}_{2}\right]$ substantially above the critical oxygen pressure for cytochrome oxidase. New Phytologist 190:431-441.

Bai, T., C. Li, C. Li, D. Liang, and F. Ma. 2013. Contrasting hypoxia tolerance and adaptation in Malus species is linked to differences in stomatal behavior and photosynthesis. Physiologia Plantarum 147:514-523.

Bai, T., C. Li, F. Ma, F. Feng, and H. Shu. 2010. Responses of growth and antioxidant system to root-zone hypoxia stress in two Malus species. Plant and Soil 327:95-105.

Bailey-Serres, J., and L.A.C.J. Voesenek. 2008. Flooding stress: acclimations and genetic diversity. Annual Review of Plant Biology 59:313-339.

Bartholomeus, R.P., J.-P.M. Witte, P.M. van Bodegom, J.C. van Dam, and R. Aerts. 2008. Critical soil conditions for oxygen stress to plant roots: Substituting the Feddes-function by a process-based model. Journal of Hydrology 360:147-165.

Bengough, A.G., M.F. Bransby, J. Hans, S.J. McKenna, T.J. Roberts, and T.A. Valentine. 2006. Root responses to soil physical conditions; growth dynamics from field to cell. Journal Experimental of Botany 57:437-447.
Bertholdsson, N.-O. 2013. Screening for barley waterlogging tolerance in nordic barley cultivars (Hordeum vulgare L.) using chlorophyll fluorescence on hydroponically-grown plants. Agronomy 3:376-390.

Blokhina, O., E. Virolainen, and K.V. Fagerstedt. 2003. Antioxidants, oxidative damage and oxygen deprivation stress: A review. Annals of Botany 91:179-194.

Blom, C.W.P.M., and L.A.C.J. Voesenek. 1996. Flooding: The survival strategies of plants. Trends in Ecology \& Evolution 11:290-295.

Bouma, T., and D. Bryla. 2000. On the assessment of root and soil respiration for soils of different textures: Interactions with soil moisture contents and soil $\mathrm{CO}_{2}$ concentrations. Plant and Soil 227:215-221.

Brady, N.C., and R.R. Weil. 2008. The nature and properties of soils. $14^{\text {th }}$ ed. 965 p. Prentice Hall, Upper Saddle River, New Jersey, USA.

Brzezińska, M., T. Włodarczyk, W. Stępniewski, and G. Przywara. 2005. Soil aeration status and catalase activity. Acta Agrophysica 5:555-565

Condon, A.G., and R.A. Richards. 1992. Exploiting genetic variation in transpiration efficiency in wheat: An agronomic view. p. 435450. In Ehleringer, J.R., A.E. Hall, and G.D. Farquhar (eds.) Stable isotopes and plant carbon-water relations. Academic Press, San Diego, California, USA.

Cook, F.J., and J.H. Knight. 2003. Oxygen transport to plant roots. Soil Science Society of America Journal 67:20-31.

da Silva, A.P., and B.D. Kay. 1997a. Effect of soil water content variation on the least limiting water range. Soil Science Society of America Journal 61:884-888.

da Silva, A.P., and B.D. Kay. 1997b. Estimating the least limiting water range of soils from properties and management. Soil Science Society of America Journal 61:877-883.

Dat, J.F., N. Capelli, H. Folzer, P. Bourgeade, and P.-M. Badot. 2004 Sensing and signalling during plant flooding. Plant Physiology and Biochemistry 42:273-282.

DeLaune, R.D., S.R. Pezeshki, and J.H. Pardue. 1990. An oxidationreduction buffer for evaluating the physiological response of plants to root oxygen stress. Environmental and Experimental Botany 30:243-247.

Dexter, A.R. 1988. Advances in characterization of soil structure. Soil and Tillage Research 11:199-238.

Drew, M.C. 1992. Soil aeration and plant root metabolism. Soil Science 154:259-268

Drew, M.C. 1997. Oxygen deficiency and root metabolism: Injury and acclimation under hypoxia and anoxia. Annual Review of Plant Physiology and Plant Molecular Biology 48:223-250.

Fassio, C., P.M. Gil, B. Schaffer, and M. Castro. 2011. Influence of rootstock on the response of 'Hass' avocado trees to flooding stress. Acta Horticulturae 889:379-383.

Feng, G., L. Wu, and J. Letey. 2002. Evaluating aeration criteria by simultaneous measurement of oxygen diffusion rate and soilwater regime. Soil Science 167:495-503.

Ferreyra, R., G. Selles, M. Pinto, M. Morales, and O. Seguel. 2011. Effect of soil air capacity on water relations and vegetative growth of 'Thompson Seedless' grafted on different rootstocks. Preliminary results. Acta Horticulturae 889:145-150.

Gliński, J., and W. Stepniewski. 1985. Soil aeration and its role for plants. CRC Press, Boca Raton, Florida, USA.

Hillel, D. 1980. Fundamentals of soil physics. Academic Press, Orlando, Florida, USA.

Imhoff, S., B. Kay, A.P. Da Silva, and M. Hajabbasi. 2010. Evaluating responses of maize (Zea mays L.) to soil physical conditions using a boundary line approach. Soil and Tillage Research 106:303-310.

Irfan, M., S. Hayat, Q. Hayat, S. Afroz, and A. Ahmad. 2010 Physiological and biochemical changes in plants under waterlogging. Protoplasma 241:3-17.

Jackson, M. 2005. Aeration stress in plant tissue cultures. p. 459473. In Hvoslef-Eide, A.K., and W. Preil. (eds.) Liquid culture systems for in vitro plant propagation. Springer, Dordrecht, The Netherlands. 
Jackson, M.B., and T.D. Colmer. 2005. Response and adaptation by plants to flooding stress. Annals of Botany 96:501-505.

Jacobs, K.A., J.D. MacDonald, A.M. Berry, and L.R. Costello. 1997. Rooting responses of three oak species to low oxygen stress. p. 91-100. In Proceedings of a Symposium on Oak Woodlands: Ecology, Management, and Urban Interface Issues, San Luis Obispo, California. 19-22 March 1996. General Technical Report PSW-GTR-160. U.S. Department of Agriculture, Forest Service, Pacific Southwest Research Station, Albany, California, USA.

Jones, C.A., W. Bland, J. Ritchie, J. Williams, and J. Hanks. 1991. Simulation of root growth. p. 91-123. In Hanks, J., and J.T. Ritchie (eds.) Modeling plant and soil systems. ASA-CSSASSSA, Madison, Wisconsin, USA.

Kozlowski, T.T. 1985. Soil aeration, flooding and tree growth. Journal of Arboriculture 11:85-96.

Kozlowski, T.T. 1997. Responses of woody plants to flooding and salinity. Tree Physiology Monograph 1(1):1-29.

Letey, J. 1985. Relationship between soil physical properties and crop production. Advances in Soil Science 1:276-294.

Logsdon, S.D. 2003. Within sample variation of oxygen diffusion rate. Soil Science 168:531-539.

McBride, M.B. 1994. Environmental chemistry of soils. Oxford University Press, New York, USA.

Mohammadi, M.H., F. Asadzadeh, and M. Vanclooster. 2010. Refining and unifying the upper limits of the least limiting water range using soil and plant properties. Plant and Soil 334:221-234.

Moldrup, P., T. Olesen, T. Komatsu, P. Schjønning, and D.E. Rolston. 2001. Tortuosity, diffusivity, and permeability in the soil liquid and gaseous phases. Soil Science Society of America Journal 65:613-623.

Moldrup, P., T. Olesen, P. Schjønning, T. Yamaguchi, and D.E. Rolston. 2000. Predicting the gas diffusion coefficient in undisturbed soil from soil water characteristics. Soil Science Society of America Journal 64:94-100.

Morard, P., and J. Silvestre. 1996. Plant injury due to oxygen deficiency in the root environment of soilless culture: A review. Plant and Soil 184:243-254.

Nickum, M.T., J.H. Crane, B. Schaffer, and F.S. Davies. 2010. Reponses of mamey sapote (Pouteria sapota) trees to continuous and cyclical flooding in calcareous soil. Scientia Horticulturae 123:402-411.

Nicolás, E., A. Torrecillas, J. Dell'Amico, and J.J. Alarcón. 2005. The effect of short-term flooding on the sap flow, gas exchange and hydraulic conductivity of young apricot trees. Trees 19:51-57.

Núñez-Elisea, R., B. Schaffer, J.B. Fisher, A.M. Colls, and J.H. Crane. 1999. Influence of flooding on net $\mathrm{CO}_{2}$ assimilation, growth and stem anatomy of Annona species. Annals of Botany 84:771-780

Perata, P., W. Armstrong, and L.A.C.J. Voesenek. 2011. Plants and flooding stress. New Phytologist 190:269-273.

Pezeshki, S.R. 2001. Wetland plant responses to soil flooding. Environmental and Experimental Botany 46:299-312.

Pezeshki, S.R., and R.D. DeLaune. 1998. Responses of seedlings of selected woody species to soil oxidation-reduction conditions. Environmental and Experimental Botany 40:123-133.

Pezeshki, S.R., J.H. Pardue, and R.D. DeLaune. 1996. Leaf gas exchange and growth of flood-tolerant and flood-sensitive tree species under low soil redox conditions. Tree Physiology $16: 453-458$

Philipson, J.J., and M.P. Coutts. 1978. The tolerance of tree roots to waterlogging. New Phytologist 80:341-349.

Pierret, A., C. Doussan, Y. Capowiez, F. Bastardie, and L. Pages. 2007. Root functional architecture: A framework for modeling the interplay between roots and soil. Vadose Zone Journal 6:269-281.

Pilatti, M.A., J. De Orellana, S. Imhoff, y Á. Pires Da Silva. 2012. Actualización de los límites críticos del intervalo hídrico óptimo. Ciencia del Suelo 30:9-21.

Pimentel, P., R.D. Almada, A. Salvatierra, G. Toro, M.J. Arismendi, M.T. Pino, et al. 2014. Physiological and morphological responses of Prunus species with different degree of tolerance to long-term root hypoxia. Scientia horticulturae 180:14-23.
Ploetz, R.R., and B. Schaffer. 1989. Effects of flooding and Phytophthora root rot on net gas exchange and growth of avocado. Phytopathology 79:204-208.

Ranney, T.G. 1994. Differential tolerance of eleven Prunus taxa to root zone flooding. Journal of Environmental Horticulture $3: 138-141$.

Ruiz-Sanchez, M.C., R. Domingo, D. Morales, and A. Torrecillas. 1996. Water relations of Fino lemon plants on two rootstocks under flooded conditions. Plant Science 120:119-125.

Sanchez-Blanco, M., J. Alarcon, J. Planes, and A. Torrecillas. 1994. Differential flood stress resistance of two almond cultivars based on survival, growth and water relations as stress indicators. Journal of Horticultural Science 69:947-953.

Scarano, F.R., and R.M.M. Crawford. 1992. Ontogeny and the concept of anoxia-tolerance: The case of the Amazonian leguminous tree Parkia pendula. Journal of Tropical Ecology 8:349-352.

Schaffer, B. 1998. Flooding responses and water-use efficiency of subtropical and tropical fruit trees in an environmentally-sensitive wetland. Annals of Botany 81:475-481.

Schaffer, B., and R.C. Ploetz. 1989. Net gas exchange as a damage indicator for Phytophthora root rot of flooded and nonflooded avocado. Hortscience 24:653-655.

Setter, T.L., and I. Waters. 2003. Review of prospects for germplasm improvement for waterlogging tolerance in wheat, barley and oats. Plant and Soil 253:1-34.

Setter, T.L., I. Waters, S.K. Sharma, K.N. Singh, N. Kulshreshtha, N.P.S. Yaduvanshi, et al. 2009. Review of wheat improvement for waterlogging tolerance in Australia and India: The importance of anaerobiosis and element toxicities associated with different soils. Annals of Botany 103:221-235.

Smith, G.S., M.J. Judd, S.A. Miller, and J.G. Buwalda. 1990. Recovery of kiwifruit vines from transient waterlogging of the root system. New Phytologist 115:325-333.

Sojka, R.E., and H.D. Scott. 2000. Aeration measurement. p. 27-29. In R. Lal. (ed.) Encyclopedia of soil science. Marcel Dekker, New York, USA.

Stępniewski, W., and Z. Stępniewska. 2009. Selected oxygendependent process-Response to soil management and tillage. Soil and Tillage Research 102:193-200.

Stolzy, H., A. Zentmyer, J. Klotz, and K. Labanauskas. 1967. Oxygen diffusion, water, and Phytophthora cinnamomi in root decay and nutrition of avocados. p. 67-76. In Proceedings of the American Society for Horticultural Science. University of California, Riverside, California, USA.

Striegler, R.K., G.S. Howell, and J.A. Flore. 1993. Influence of rootstock on the response of Seyval grapevines to flooding stress. American Journal of Enology and Viticulture 44:313-319.

Striker, G.G. 2008. Visiting the methodological aspects of flooding experiments: Quantitative evidence from agricultural and ecophysiological studies. Journal of Agronomy and Crop Science 194:249-255.

Striker, G.G. 2012. Time is on our side: The importance of considering a recovery period when assessing flooding tolerance in plants. Ecological Research 27:983-987.

Taiz, L., and E. Zeiger. 2010. Plant physiology. $5^{\text {th }}$ ed. Sinauer Associates, Sunderland, Massachusetts, USA.

Tavakkoli, E., P. Rengasamy, and G.K. McDonald. 2010. The response of barley to salinity stress differs between hydroponic and soil systems. Functional Plant Biology 37:621-633.

Tete, E., V. Viaud, and C. Walter. 2015. Organic carbon and nitrogen mineralization in a poorly-drained mineral soil under transient waterlogged conditions: an incubation experiment. European Journal of Soil Science 66:427-437.

Unger, P.W., and T.C. Kaspar. 1994. Soil compaction and root growth: A review. Agronomy Journal 86:759-766.

Valoras, J., J. Letey, H. Stolzy, and E.F. Frolich. 1964. The oxygen requirements for root growth of three avocado varieties. p. 172178. In Proceedings of the American Society for Horticultural Science. University of California, Riverside, California, USA. 
Vartapetian, B.B., and M.B. Jackson. 1997. Plant adaptations to anaerobic stress. Annals of Botany 79:3-20.

Visser, E., and L. Voesenek. 2005. Acclimation to soil flooding sensing and signal-transduction. p. 197-214. In Lambers, H., and T. Colmer (eds.) Root physiology: from gene to function. Springer, Dordrecht, The Netherlands.

Whitmore, A.P., and W.R. Whalley. 2009. Physical effects of soil drying on roots and crop growth. Journal Experimental of Botany 60:2845-2857.

Wu, L., G. Feng, J. Letey, L. Ferguson, J. Mitchell, B. McCulloughSanden, et al. 2003. Soil management effects on the nonlimiting water range. Geoderma 114:401-414.
Yetisir, H., M.E. Çaliskan, S. Soylu, and M. Sakar. 2006. Some physiological and growth responses of watermelon [Citrullus lanatus (Thunb.) Matsum. and Nakai] grafted onto Lagenaria siceraria to flooding. Environmental and Experimental Botany $58: 1-8$.

Zhang, J., and X. Zhang. 1994. Can early wilting of old leaves account for much of the ABA accumulation in flooded pea plants? Journal Experimental of Botany 45:1335-1342.

Zschornack, T., C. Bayer, J.A. Zanatta, F.C.B. Vieira, and I. Anghinoni. 2011. Mitigation of methane and nitrous oxide emissions from flood-irrigated rice by no incorporation of winter crop residues into the soil. Revista Brasileira De Ciencia Do Solo $35: 623-634$. 